\title{
INFECÇÕES HOSPITALARES NO BRASIL. AÇÕES GOVERNAMENTAIS PARA O SEU CONTROLE ENQUANTO EXPRESSÃO DE POLÍTICAS SOCIAIS NA ÁREA DE SAÚDE*
}

\author{
Rúbia Aparecida Lacerda** \\ Vanda Maria Galvão Jouclas** \\ Emiko Yoshikawa Egry***
}

LACERDA, R.A. et al. Infecçōes hospitalares no Brasil. Ações governamentais para o seu controle enquanto expressões de políticas sociais na área da saúde. Rev.Esc.Enf.USP, v.30, n.1, p.93-115, abr. 1996.

As autoras estudam a evolução das infecções hospitalares no Brasil e as demandas para o seu controle até a sua institucionalização, por ações governamentais. Para a compreensão e análise do processo de disputa dos interesses e necessidades dos atores sociais e sua relação com o setor governamental para a institucionalização de uma dada política pública, buscou-se um referencial teórico que possibilitasse elaborar o conjunto dos elementos da estrutura social e que tomasse o campo da relação entre Sociedade, Estado e Políticas Sociais como sua questão central. Por referência à especificidade dessas ações e seu raio de intervenção, foi necessário buscar também a distinção de modalidades de políticas públicas e a responsabilidade de implementação. A partir do material empírico, foi possivel delinear essas demandas, conformando-as em modelos tecno-assistenciais, através de indicadores do processo de trabalho. Sua aproximação com o referencial teórico exigiu outros niveis de categorias: conjunturas especificas, assistência médica previdenciária, modelo clínico de intervenção e o movimento de qualidade. A análise das demandas e do projeto institucionalizado buscou, o tempo todo, a relação dos seus instrumentos e finalidades com eles mesmos e com as politicas mais gerais do setor saúde, mostrando as suas implicações.

UNITERMOS: Infeç̧ão hospitalar. Políticas de Saúde.

\footnotetext{
* Baseado na tese de doutorado de LACERDA, R.A., de mesmo título, defendida em maio de 1995, na Escola de Enfermagem da USP

* Enfermeiras. Professoras Doutoras do Departamento de EnfermagemMédico-Cirúrgica da Escola de Enfermagem da Universidade de São Paulo.

*** Enfermeira. Professor Livre Docente do Departamento de Enfermagem em Saúde Coletiva da Escola de Enfermagem da Universidade de São Paulo.
} 


\section{INTRODUÇÃO E REFERENCIAL TEÓRICO DE ANÁLISE}

Este trabalho se propôs a realizar um estudo sobre as ações governamentais para o controle de infecções hospitalares (IHs) no Brasil, entendendo-as como expressão de políticas sociais na área de saúde. Tratouse, portanto, de penetrar no campo das políticas públicas e nas complexas relações que se estabelecem entre seus formuladores e as políticas governamentais, para a institucionalização e implementação dessas ações. Antes, porém, algumas considerações iniciais sobre este objeto de estudo fizeram-se necessárias, por assim dizer, como um ponto de partida, que permitiss em reconhecê-lo e justificá-lo como problema a ser investigado.

Considere-se então, que a ocorrência de IHs tem se constituído em importante problema de saúde pública no Brasil e no mundo. Entretanto, apesar desse reconhecimento generalizado nos últimos anos, é preciso observar que a sua ocorrência é muito antiga. Considerando as IHs como toda infecção adquirida ou transmitida no ambiente hospitalar, sua origem pode ser buscada na Idade Média, período em que foram criados os primeiros hospitais e as práticas para o seu controle, na reorganização do hospital, quando este passou de um local de exclusão para um local de cura, na emergência do capitalismo e no início do desenvolvimento do modelo clínico de assistência.

Uma questão que se colocou para este estudo foi compreender como e porquê, as IHs, que já existiam desde a Idade Média, em determinado momento histórico-social de formação capitalista e de desenvolvimento do modelo clínico de assistência (a partir da década de 50), extrapolaram as preocupações e o âmbito da prática clínica, tornando-se reconhecidas como problema de saúde pública e sendo amplamente discutidas na mídia, nos eventos científicos, inclusive, nos organismos internacionais como a OMS e a OPAS, culminando com ações governamentais para o seu controle no Brasil, a partir da década de 80 .

De outra forma, procurou-se também compreender, a partir das discussões no país, as ações que se institucionalizaram para a identificação e o controle do problema, quais as suas finalidades e a que necessidades atendiam. Em outras palavras, buscou-se neste estudo, o significado do controle das IHs no contexto de saúde de uma dada formação social concreta, que é o caso do Brasil.

Antecipe-se porém, que as IHs, tal como ocorrem hoje, não podem ser consideradas como doenças infecciosas quaisquer, mas como conseqüência de um modelo de organização assistencial e tecnológico baseado no saber clínico. Já, as práticas para o seu controle baseiam-se em outro saber, o epidemiológico. 
Tal situação implicou colocar em evidência esses dois modelos predominantes de assistência à saúde de que dispomos atualmente: o clínico e o epidemiológico. Resumidamente, o clínico visa essencialmente a cura do indivíduo doente, com intervenções na dimensão individual (corpo biológico) e com sua prática predominante no hospital. O epidemiológico visa essencialmente a prevenção e a promoção da saúde individual e coletiva através da atuação em dimensões coletivas, com sua prática predominante no campo da saúde pública.

Porém, concordando com MERHY (1991), tal distinção não se mostra suficiente para a compreensão desses saberes e sua repercussão na formulação de políticas de saúde nesses dois campos, uma vez que, sabidamente, ambos têm utilizado a clínica e a epidemiologia como seus instrumentos de ação. $\mathrm{O}$ uso da epidemiologia para o CIH, portanto, não é uma exceção.

Para avançar nessa questão, foi preciso buscar as condições em que esses modelos tecnologicos (saberes) são utilizados nesses campos em dado momento histórico-social, configurando então determinados processos de trabalho, ou aquilo que MERHY (1991:4) denomina de ações tecnoassistenciais, isto é, "... ações que expressam uma dada construção do que é objeto saúde-doença, expressando uma maneira particular de organizar a produção dessas ações como serviços ".

Vale então dizer que, ao buscar a compreensão do CIH como ação de políticas governamentais, não bastou somente analisar o processo de trabalho que se institucionalizou, mas também as condições histórico-sociais em que essas ações foram reconhecidas como necessidade e como e porquê um determinado projeto foi aprovado, dentre outros possíveis.

Sendo assim, uma hipotese para este estudo foi que a evolução das IHs no país está relacionada não somente com a evolução do modelo clínico de assistência (e de suas práticas diagnósticas e terapêuticas invasivas e imunossupressivas no corpo biologico), mas tambem com a forma com que essa assistência foi politicamente conduzida, manifestando-se o seu aspecto particular, que foi imprescindível analisar para superar a sua compreensão, além de sua expressão enquanto fenômeno mundial e meramente biológico.

Por tese, as ações governamentais para o CIHs a partir da década de 80 , no Brasil, foram parte e decorrência de ações de controle sanitário mais gerais que começaram a institucionalizar-se a partir de 74 , sob o reconhecimento da necessidade de uma reconversão da política de saúde adotada até então. Dentre essas medidas, destaque-se a criação da Secretaria de Vigilância Sanitária (SNVS), cujas ações se estenderam, inclusive, às práticas diretamente relacionadas com a saúde e seus estabelecimentos.

Essas ações de vigilância sanitária, mesmo com raios de intervenção mais específicos e setorizados, não podem deixar de serem consideradas também como políticas públicas, ao se basear no seu conceito dado por COSTA 
( s.d.): “... espaço de tomada de decisão (ou de não decisão) autorizada ou sancionada através de atores governamentais, compreendendo atos que visam responder alguma demanda de grupos ou de classes sociais".

Para tanto e, concordando com MERHY (1991), observou-se a necessidade de usar um referencial teórico que elaborasse de forma ampla o conjunto dos elementos da estrutura social e que tomasse o campo da relação entre Estado, Sociedade e Políticas Sociais como sua questão central. Portanto, foi preciso entender, nesse campo, o processo de disputa de vários interesses e seus projetos e de suas relações como os atores governamentais para a institucionalização de uma dada política pública.

De outra forma, para compreender os movimentos sociais por políticas de CIHs até a sua institucionalização, foi preciso também elaborar uma análise sobre o papel dos atores sociais, mostrando sua inserção no jogo político e que não bastavam as suas demandas, sendo preciso que se apresentasse um projeto.

Dada também a característica que este estudo solicitou, que foi trabalhar políticas públicas com raios de intervenção mais setorizados, foi preciso entender que a especificidade da ação governamental também é um fator que interfere na relação Estado-Sociedade-Políticas Sociais. Isso exigiu uma delimitação dos tipos e variedades de políticas públicas e das formas de organização de interesses dos atores que pudessem ser aplicáveis à arena setorial de saúde em um dado contexto histórico. Tal delimitação foi entendida enquanto:

a) modalidade de política pública - segundo COSTA (s.d.), pode ser distributiva, redistributiva (o caso doSUS), auto-regulatória e regulatória (o caso do CIH);

b) responsabilidade de implementação - podendo ser estatal ( o caso do SUS) e extra-estatal (o caso do CIH), conforme OFFE \& LENHARDT (1984).

De outra forma, foi preciso também verificar como elas se interrelacionam, levando a complementações ou contradições.

Essa relação é determinada também, segundo MARTINS (1985), pelas especificidades que assumem as formas e os momentos de desenvolvimento das sociedades. No caso brasileiro, algumas delas puderam ser verificadas: a desarticulação social, a articulação entre os interesses públicos e privados, a assistência curativa e preventiva e a captação e distribuição de recursos.

Para reconhecer essas relações, outro momento se apresentou necessário, que foi a análise de sua implementação, ou seja, como uma ação se comporta na prática que, conforme LUZ (1979), constitui-se um momento privilegiado para conhecer as contradições, dadas pelas respostas dos que são instituídos por elas e que incluem diferentes niveis e formas de resistências. 
Isso mostra então, para OFFE \& LENHARD'T (1984), que há processos de poder que se intercalam entre a realidade legal e a social da política social estatal, sendo que a "...tarefa de uma pesquisa sociologica sobre política social não pode ser vista somente na formulação prescritiva de metas e de resultados, mas sim, na elucidação descritiva das condições sociais de implementação da regulamentação política".

Com relação ao Estado e. concordando com esses mesmos autores, no desenvolvimento de uma política social, é preciso também considerar que o Estado reage tanto aos interesses dos conflitos sociais quanto às necessidades de organização das estruturas internas do seu sistema político e do seu processo de acumulação e que essas duas situações se comportam de maneira contraditória. (OFFE \& LENHARDT, 1984).

Diante disso, os objetivos deste estudo foram:

- explicitar os movimentos das demandas sociais por políticas de controle de IHs no Brasil, inseridos em conjunturas específicas, determinadas pelos rumos do desenvolvimento econômico-social do país, a partir da década de 50 ;

- compreender como e porquê as ações governamentais de CIHs foram institucionalizadas em determinado momento historico-social;

- reconhecer, a partir dessas ações, o processo de trabalho que se instalou para o controle das IHs;

- analisar a relação dessas ações governamentais com as demandas sociais e as políticas mais gerais para a área da saúde, a partir da sua implementação.

\section{MÉTODO DE ANÁLISE}

O presente estudo buscou uma investigação qualitativa, na área das ciências sociais. O método de análise adotado foi o histórico e dialético, por acreditá-lo o mais fecundo para analisar os fenômenos sociais, ao privilegiar, dentre outros aspectos, segundo DEMO) apud por Minayo ( 1992): a) a contração e o conflito predominando sobre a harmonia e o consenso; b) o fenômeno da transição, da mudança, do vir-a-ser sobre a estabilidade; c) o movimento histórico; d) a totalidade e a unidade dos contrários. Este estudo buscou, portanto, uma análise crítica histórica e essencialmente política.

Análise crítica e histórica porque procurou ir além de uma discussão historiográfica da evolução das IHs e de suas práticas de controle, tentando evidenciar as suas contradições na relação com elas mesmas e na relação com o Estado, a Sociedade e as políticas sociais mais abrangentes. 
Análise política, porque procurou descobrir nessas ações, segundo LUZ (1979), a representação de modos de poder de um modo de produção social, evitando reduzi-las a mero reflexo de evolução das forças produtivas ou à função de reprodutoras das relações sociais de produção.

Com relação à opção tomada nesse estudo, que foi trabalhar com o significado do porquê essas ações governamentais ocorreram num dado momento histórico-social, somente a sua "leitura" não foi suficiente para abarcar toda uma dinâmica social complexa. Foi preciso então, uma análise retrospectiva, para compreender as origens das demandas e as concepções que se delineavam para o seu controle pelos diferentes grupos sociais e o rumo que elas tomaram até a institucionalização daquela que se hegemonizou.

\section{PERCURSO EXPLORATÓRIO}

\subsection{Fonte de dados empiricos}

Para reconhecer essas demandas e suas concepções, o material empírico coletado, além das ações governamentais, constou também: a) estudos e pesquisas nacionais publicados; b) eventos científicos de maior repercussão, inclusive aqueles internacionais que discutiram políticas para o seu controle na América Latina; c) entrevistas; c) reportagens na mídia escrita.

Os dados foram organizados por década, a partir de 1950. A opção por iniciar a coleta nesse período justificou-se por ter sido a partir de meados deste século, que a repercussão das Ihs começou a ampliar-se no mundo, além da prática hospitalar, quando reconheceu-se a sua nova forma de manifestação: endogenas e multi-resistentes, dadas principalmente pelo aumento do uso de antibióticos e o avanço das tecnologias invasivas.

\subsection{Tratamento dos dados}

O que se buscou interpretar nos dados, foram as demandas por CIH até a sua institucionalização, por ações governamentais. Essas demandas foram apreendidas como modelos tecno-assistenciais, que se expressam na forma de processos de trabalho específicos, devendo revelar, portanto, os seus elementos constitutivos, na forma de concepção do objeto, os instrumentos de intervenção, as finalidades e os agentes. (O quadro I, em anexo, mostra os principais processos apreendidos, a partir do material empírico.

Para interpretar as conexões dessas categorias empíricas com as categorias analíticas mais abrangentes-Estado, Políticas Sociais,Sociedadefoi necessário buscar também outras categorias de aproximação, que permitissem encontrar nesses dados empíricos, a partir de sua significação particular, a representação da totalidade. 
Essas categorias de aproximação basearam-se nos seguintes niveis temáticos, dados por MINAYO (1992): a) conjuntura sócio-econômica e política na qual se inseriram os grupos sociais que demandaram esses processos; b) história dos grupos e sua inserção na produção e suas condições de reprodução; c) políticas de saúde em geral e em particular; d) instituições de saúde às quais os grupos em questão tinham acesso.

Dada a característica desse objeto de estudo (IH) valorizou-se, nas ações de saúde, o modelo clínico de assistência, sua forma predominante de institucionalização, pela assistência médica previdenciária e a qualidade na assistência à saúde.

\subsection{Periodização}

A análise desses dados foi dividida em 3 períodos: 1950 a $1967 ; 1968$ a $1974 ; 1980$ a 1990 . As razões para essa divisão serão justificadas no decorrer da análise.

\section{EVOLUÇÃO HISTÓRICO-SOCIAL DAS INFECÇÕES HOSPITALARES E DE SUAS PRÁTICAS DE CONTROLE}

Antes da análise dessas demandas no Brasil, outro momento se mostrou necessário: compreender a evolução histórico-social das IHs e de suas práticas de controle desde a Idade Média, permitindo mostrar a relação estreita dos tipos de ocorrência de IHs com a própria história das concepções dominantes do processo saúde-doença e de suas formas de intervenção no hospital. Esclareça-se que nessa evolução, um tipo de ocorrência de IH não desapareceu para dar lugar a outro, apenas foram apresentando momentos de maior ou menor expressão, conforme as práticas hospitalares dominantes. $O$ quadro II, em anexo, classifica, resumidamente, essas formas de ocorrência.

\section{AS INFECÇÕES HOSPITALARES E SUAS PRÁTICAS DE CONTROLE NAS DÉCADAS DE 50 E 60 NUM CONTEXTO DE DESENVOLVIMENTO DA ASSISTÊNCIA MÉDICA NO BRASIL}

\subsection{A conjuntura do período de 1950 a 1966 e as políticas de saúde}

A década de 50 até meados de 60 representaram a fase final de uma política nacional de saúde que iniciou-se a partir de 30 , contemplando as transformações ocorridas com a Revolução de 30 e uma nova forma de evolução 
do Estado Brasileiro, que foi destruindo o excessivo federalismo da Primeira República e dando início a um processo de centralização e elevado grau de autonomia, determinando então, para DRAIBE (1985), o início da formação do Estado nacional moderno, no sentido de ser um orgão (político) que tende a afastar-se dos interesses imediatos e a sobrepor-se ao conjunto da sociedade como soberano.

No plano econômico, a partir de 30, o Estado procurou superar o padrão de acumulação anterior (primário-exportador), instaurando um processo de industrialização, caracterizado em duas fases: a primeira, entre 1933 e 1955 , baseando-se na produção de bens manufaturados não duráveis destinados ao consumo final (FURTADO, 1981). A segunda, entre 1956 e 1961 principalmente com o plano de metas de Juscelino Kubitschek -, baseando-se na industrialização pesada (DRAIBE, 1985).

Nesse contexto político e econômico, as políticas sociais evoluíram no sentido de contemplar o trabalho assalariado urbano, incluindo de forma centralizada e autônoma legislações trabalhistas, montagem do sistema previdenciário baseado nos Institutos de Aposentadorias e Pensões (IAPS), sindicalismo atrelado ao Estado, etc., procurando assim, estabelecer, segundo BRAGA \& PAULA (1980), níveis mínimos de reprodução de força de trabalho, tendo sob controle a participação política dos trabalhadores e, ao mesmo tempo, mantendo a lucratividade do setor industrial.

Já, a política de saúde ficou centralizada em dois subsetores: o de saúde pública e o de medicina prevideenciária, mantendo-se o primeiro predominante até o início da década de 60.

O subsetor de medicina previdenciária, apresentava nesse período, segundo BRAGA \& PAULA (1980), uma taxa excedente, com gastos maiores com aposentadorias e pensões do que com assistência médica.

Portanto, até aí, a "explosão de hospitais ainda não acontece, assim como, a rápida assimilação de novas tecnologias médicas já iniciadas nos países mais avançados após a Segunda Guerra, dadas principalmente, pela evolução das indústrias farmacêuticas e de equipamentos hospitalares.

\subsection{As infecções hospitalares e as demandas por controle na década de 50}

Através da análise do material empírico, constatou-se que já havia demanda para o CIHs, ainda que pequena e restrita aos profissionais dos hospitais. As publicações existentes, praticamente, não podem ser consideradas como investigações científicas nacionais, baseando-se principalmente em dados da literatura científica internacional. As concepções predominantes para a ocorrência dessas infecções eram ambiental e procedimental, fornecidas principalmente por administradores e enfermeiros. Como exemplo, vide FRANCISCONI (1959) e CHISTÓVĨ̃O (1956). 


\subsection{A conjuntura de 1961 a 1964 e a situação da saúde}

O início da década de 60 revelou uma situação de crise na sociedade, reconhecendo-se o final da segunda fase do processo de industrialização no país, ao prenunciar-se os elementos de esgotamento da intervenção do Estado, cujo desenvolvimento, segundo DRAIBE (1985), vinha sendo pautado no privilegiamento da entrada maciça de capital e de tecnologias estrangeiras em áreas novas, através de incentivos, isenções e facilidades. Se, de um lado, essa política propiciou um salto para o desenvolvimento industrial e a integração da economia ao esquema internacional do pós-guerra (DRAIBE, 1985), de outro, essa expansão foi feita sem a devida preocupação com as conseqüências sociais que adviriam do enxerto, em uma sociedade pobre e com características particulares, dos padrões de tecnologia e de consumo de sociedades mais avançadas, em que a riqueza e sua distribuição por habitante e muitas vezes superior (FURTADO, 1981).

Do ponto de vista social, esse Estado conformou-se sob os interesses agrário-exportadores, a pressão de uma burguesia industrial em rápido processo de formação e diferenciação, as injunções e demandas de uma ampla masssa assalariada urbana em rapidíssimo processo de constituição e diferenciação que clamava por previdência social, saúde, habitação, educação, melhores condições de vida, liberdade de participação nas decisões, etc. (DRAIBE, 1985).

Com isso, na assistência à saúde, o país adentrou a década de 60 também em crise, crescendo a demanda por assistência médica, enquanto deterioravase a situação econômico-financeiro do sistema, ao mesmo tempo em que não foram resolvidos os problemas no subsetor de saúde pública, aumentando ainda mais a demanda por assistência médica (BRAGA \& PAULA, 1981).

\subsection{As infecções hospitalares na década de 60 e as demandas por controle}

As publicações nacionais sobre IHs nesse período já mostravam as tendências de sua evolução na década seguinte. Embora com repercussão ainda restrita ao meio hospitalar, elas ampliam-se com relação à década de 50 , mostrando a sua relação com o aumento das demandas por assistência médica e as internações hospitalares.

Além da permanência das concepções ambiental e procedimental, discutidas principalmente por administradores e enfermeiros, difunde-se largamente a concepção de flora humana, predominantemente através dos médicos, com o reconhecimento das infecções causadas por microorganismos endógenos e multi-resistentes. Aparecem assim, os estudos bacteriologicos sobre comportamento e resistência dessa flora endogena e o aumento do uso terapêutico e profilático de antibióticos. (Como exemplo, vide MACHADO et al, 1961). 


\subsection{As respostas à crise da conjuntura 1961 a 1964 e as politicas de saúde}

Sabidamente, no plano político e econômico, à crise do modelo desenvolvimentista populista desse período e aos intensos movimentos sociais, o Estado respondeu com uma nova articulação de forças sociais - os militares e as frações hegemônicas da burguesia - instaurando no país um poder autoritário (ditadura militar) e um modelo de desenvolvimento econômico conhecido como o "milagre brasileiro".

No plano das políticas sociais, a crise na área da saúde se "resolveu" com a reforma da medicina previdenciária e a unificação dos Institutos de Aposentadorias e Pensões (IAPs) a partir de 1966, criando o Instituto Nacional de Previdência Social (INPS), ao mesmo tempo em que a saúde pública ficou relegada a segundo plano. A partir daí, deu-se o início da "explosão" dos hospitais e da assis tência médica privada e conveniada, cujos resultados serão analisados na conjuntura seguinte.

\section{A ASSISTÊNCIA MÉDICA NA CONJUNTURA 68-74 E SEUS REFLEXOS NA EVOLUÇÃO DA OCORRÊNCIA DAS INFECÇÕES HOSPITALARES}

\subsection{A conjuntura econômica, social e politica}

Esse período marcou a primeira fase da ditadura militar no país, quando se adotou um modelo de desenvolvimento econômico conhecido como o "milagre brasileiro", pautado no tripé empresa nacional, empresa multinacional e o Estado.

A partir de meados da década de 70 , com a crise internacional do petróleo, observou-se o fim do crescimento econômico, mostrando a fragilidade desse modelo de desenvolvimento que conduziu, dentre outras situações, à urbanização caótica e acelerada, à concentração de renda, aos baixos salários e ao desemprego. A saúde pública ficou relegada a segundo plano e observouse o recrudescimento das doenças infecciosas (das quais a epidemia de meningite em São Paulo foi um exemplo) e o crescimento das doenças crônicodegenerativas e por causas externas (LUZ, 1979 e ROSSI, s.d.).

A insatisfação do proletariado somou-se a da burguesia, por mudanças no modelo adotado e com denúncias na mídia sobre a situação social e de saúde da população. 


\subsection{A assistência médica e as infecções hospitalares}

A assistência médica, priorizada pelo Estado, levando à "explosão" dos hospitais, não resultou à população, em momento algum, a garantia de acesso e de melhoria na qualidade da atenção.

E preciso lembrar que o Estado, ao unificar os Institutos de Aposentadorias e Pensões (IAPS) e criar o INPS em 1966, se de um lado, veio atender aos interesses das demandas por acesso e melhoria da qualidade na assistência (que até então era feita desigualmente pelos diferentes IAPS), de outro, respondeu tambem às necessidades do seu projeto de desenvolvimento e de acumulação. Assim, essa unificação priorizou um tipo de assistência sabidamente caracterizada pela prática curativa, individual, especializada e tecnicista, com forte absorção de tecnologia de ponta e cara, indicando o interesse do Estado em se articular com o capital inaternacional e, nessa situação específica, com a expansão das indústrias farmacêuticas e de equipamentos hospitalares. Tal processo foi favorecido ainda mais com a Reforma Universitária no período, conduzindo à formação de especialistas para atender a essas necessidades (OLIVEIRa \& TEIXEIRA, 1989).

Nesse caminho, o Estado priorizou também a assistência privada, cuja forma de convênio com o INPS acarretou o sucateamento dos hospitais públicos, a manutenção e ampliação da desigualdade na assistência e a corrupção, com o aumento das internações e dos atos médicos desnecessários. De outra forma, o acesso manteve-se restrito àqueles formalmente inseridos no mercado de trabalho.

Com esse modelo assistencial, o país rapidamente integrou-se aos centros mais avançados, respondendo quase simultaneamente com a era da circulação extra-corpórea e dos transplantes de órgãos. Mas, o país entrou também e, definitivamente, na era das IHs "modernas": endogenas e multiresistentes, tendo em vista as características dessa tecnologia assistencial, de intervenções diagnósticas e terapêuticas altamente invasivas e imunossupressivas.

Todavia, essas infecções também apresentaram sua face "modernaparticular", pelo modo próprio com que essa assistência foi politicamente introduzida, tendo a ver com sua distribuição, intensidade e utilização.

Assim, a partir de meados da década de 70, os dados empíricos mostram um aumento das demandas por controle das IHs, seja através da mídia (ainda timidamente), seja através de cursos e eventos científicos e na multiplicação da produção científica nacional. Os dados mostram também o reconhecimento, pelos profissionais da área hospitalar, das várias formas de ocorrência dessas IHs (exógenas específicas, inespecíficas e endógenas resistentes ou não) e sua relação com as condições da assistência médica. Estão presentes também todas as concepções para sua transmissão: ambiental, procedimental, flora 
humana, múltipla e multicausal. Sob essa última, tomou força a demanda para o seu controle pelos profissionais da área hospitalar, através da criação de Comissões de Controle de Infecção Hospitalar (CCIHs) e utilizando a Vigilância Epidemiologica como seu instrumento de ação.

\subsection{As respostas governamentais}

Sob a necessidade de mudanças governamentais para contornar a crise do primeiro período da ditadura, especificamente no setor saúde, foi criado o Sistema Nacional de Saúde (SNS) em 1975, sob a Lei 6229, propondo a integração da Medicina Previdenciária e a Saúde Pública e cabendo ao Ministério da Saúde formular a política nacional de saúde RUIZ, S.D.).

Entretanto, conforme BRAGA \& PAULA (1985), essa tentativa foi obstaculizada, na medida em que não se modificaram em termos políticos, financeiros e administrativos, as então prioridades atribuídas à atenção médica curativa e à privatização da medicina. Ou seja, persistiram os reduzidos gastos do Estado com a saúde pública e o segmento hospitalar manteve os enormes recursos assegurados através dos repasses da Previdência Social.

Mesmo diante do reconhecimento da crise previdenciária em 1977 (dados pelos custos exorbitantes e crescentes dessa assistência e pela corrupção) e as tentativas de racionalização, como a criação do SINPAS, essa situação não se modificou. Resultaram disso, o agravamento da situação da saúde em geral adentrando a década de 80 e a ampliação da crise da Previdência, constituindo importantes reforços para a expansão de uma outra forma de assistência médica: a medicina de grupo, na década de 80. Já, o movimento contra-hegemônico da Reforma Sanitária, que começou a repercutir nesse periodo, ainda teve que aguardar o final da década de 80 , para que suas proposições fossem institucionalizadas na Constituição de 88.

No plano mais específico, para tentar resolver as péssimas condições sanitárias na prestação e produção de serviços nos diversos setores, a Secretaria Nacional de Vigilância Sanitária (SNVS), sob o MS, es tabeleceu várias ações, entre elas, o Decreto 77.052/76 (BRASIL: 1976), dispondo sobre a fiscalização sanitária das condições de exercício de profissões e ocupações técnicas diretamente relacionadas com a saúde e a Lei 6437/77 (BRASIL:1977), estabelecendo as sanções respectivas e outras providências.

Já, as demandas mais específicas para o controle das IHs, só encontraram eco nesse período, no MPAS, que solicitou a criação de CCIHs, porém somente nos seus hospitais próprios. Mesmo assim, nunca se soube quantos desses hospitais acataram essa decisão, já que não houve fiscalização. 


\section{ANOS 80: O "BOOM"DAS INFECÇÕES HOSPITALARES NO BRASIL. AS DEMANDAS POR CONTROLE NUM CONTEXTO DE CRISE DA ASSISTÊNCIA MÉDICA PREVIDENCIÁRIA}

\subsection{As demandas por controle das infecções hospitalares nos jornais}

As ocorrências de infecções hospitalares simplesmente "explodiram" na mídia na década de 80. Ao aumento das demandas dos profissionais da área hospitalar juntaram-se as denúncias da clientela. As causas foram buscadas por todos os lados: deficiência de recursos humanos e materiais, baixos salários, sucateamento das instalações e dos equipamentos, planta física inadequada, problemas de limpeza, abuso no uso de antibioticos, superlotação, pacientes debilitados, etc. Em última instância, as críticas centraram "fogo"na Previdência Social, com reclamações sobre o repasse insuficiente de verbas ou a falta de critérios para o credenciamento dos hospitais.

Assim, a repercussão das IHs não vieram sozinhas, mas como situação integrante da péssima situação da saúde no país, inclusive na assistência médica. Nesta, assistiu-se o clímax da crise da Previdência que, conforme OLIVEIRA \& TEIXEIRA (1989), se apresentou em 3 momentos: crise ideológica (1980), mostrando claramente a divisão dos interesses privados e da população; crise financeira (1981), com a falência do sistema sendo divulgada pelo próprio governo; crise político-institucional (1982). Às crises, seguiram-se uma série de tentativas de reformulação, como o PREV-SAÚDE (1980), O CONASP (1981), as AIS, o SUDS e, finalmente, a reforma ampla sob os princípios do movimento contra-hegemônico, institucionalizando o SUS, a partir de 88 .

Enquanto isso, crescia o setor importante da medicina de grupo, ocupando os espaços deixados pela péssima qualidade da assistência da Previdência. Esses espaços foram sendo ocupados com a absorção dos grupos sociais de melhor renda, justamente no momento em que a reforma sanitária demandava e pressionava pela universalização da assistência.

A se pensar que a assistência privada e conveniada com a medicina de grupo não estivesse apresentando problemas semelhantes de qualidade de assistência, as informações nos jornais do período mostravam claramente que não. Era justamente a clientela desses tipos de assistência que denunciava nos jornais, inclusive, com tentativas de se criar uma associação dos vitimados e dos seus parentes contra a ocorrência de IHs, mostrando claramente que esse problema não estava presente somente nos hospitais próprios e conveniados da Previdência (ASSOCIAÇÃO), 1983). 


\subsection{0 processo de redemocratização da sociedade brasileira e as politicas sociais.}

A década de 80 foi marcada pelo final da ditadura militar e a transição democrática, concretizada em 89 , com a primeira eleição de um presidente civil. No plano político, o período foi considerado como a década politicamente "ganha", pelas importantes conquistas obtidas: legis lação abundante para a garantia de cidadania, com tentativas de atender os interesses diversos e antagônicos. Já, no plano econômico, o período tem sido considerado como década "perdida", tendo passado por uma crise econômica sem precedentes e colocando em risco as conquistas de cidadania adquiridas (FIORI \& KORNIS. 1994).

Foi nesse contexto de crise econômica geral e da saúde em particular, que as primeiras ações para o controle das IHs foram institucionalizadas, assunto que será abordado no próximo item.

\subsection{As ações governamentais para controle das infecçóes hospitalares}

A primeira ação governamental efetiva para o controle das IHs foi a Portaria 196 de 24 de junho de 1983, sob o MS, determinando que "todos os hospitais do país deverão manter Comissões de Controle de Infecção Hospitalar (CCIHs), independentemente da natureza da entidade mantenedora" (BRASIL, 1983). Ela forneceu também as orientações para a organização do processo de trabalho dessa comissão, caracterizando os seus agentes e suas atividades.

Para que essa ação, dessa forma e. nesse momento histórico-social se configurasse, é preciso considerar a conjugação de uma série de fatores concorrendo com seus interesses e necessidades específicos, nos níveis externos e internos. No nível interno, há que se considerar o reconhecimento amplo do aumento das iatrogenias da assistência médica dadas pela forma própria de assistência do modelo clínico e de sua qualidade. De outra forma, tratou-se também de um momento de abertura política, conduzindo ao crescimento dos movimentos sociais e suas demandas.

No nível externo, considere-se a pressão dos movimentos internacionais, inclusive a OMS e a OPAS, para a adoção de políticas de controle dessas infecções. Além disso, outras causas podem ser buscadas: o reconhecimento generalizado do aumento dos gastos com o tratiamento dessa iatrogenia, na repercussão das ações legais impetradas pela clientela ( principalmente dos E.U.A.); o interesse dos proprietários da assistência médica e dos fornecedores de tecnologia (indústrias farmacêuticas e de materiais e equipamentos hospitalares), em não permitir transparecer o paradoxo do modelo clínico ao mesmo tempo que cura, causa doenças. 
O processo de trabalho que se institucionalizou sob essa ação governamental foi aquele oriundo do movimento dos profissionais dos hospitais que, dentre todas as demandas que repercutiam na sociedade, foram eles os atores que apresentaram um projeto específico para o controle do problema. Esse processo, nada mais era do que o projeto americano.

Portanto, tratou-se de um projeto universal que, ao não levar em consideração a situação particular da assistência à saúde no país e sua relação com as IHs, necessariamente, apresentou suas contradições.

Comece-se com a sua implantação que, no âmbito ministerial, evidenciou-se a difícil articulação dos MS e MPAS, já que essas ações emanaram do MS, cabendo sua execução nos hospitais, ao o âmbito do MPAS. Essas ações acabaram tendo um caráter não obrigatório sendo que, apesar das solicitações do grupo técnico que se formou no Ministério da Saúde para redigir esse processo de controle, o INAMPS não condicionou o credenciamento dos hospitais à existência de CCIHs.

Com relação à implementação, olsservou-se que o tipo de política adotada foi regulatória e com responsabilidade de implementação extra.estatal, ou seja, o Ministério da Saúde estbeleceu o processo de trabalho, mas não os recursos, portanto, não garantindo uma proteção governamental unívoca para toda a clientela.

Assim, apesar de existir uma política que, em tese, regia igualmente as ações de CIH nos vários serviços, por esses se darem em diferentes níveis de assistência, a implementação não poderia se estabelecer de forma igual. Portanto, a implantação e implementação dessas ações acabaram dependendo das condições apresentadas pelos diferentes hospitais, de suas interpretações, nas resistências encontradas e nos processos de poder que se intercalariam no curso de sua operacionalização.

Outra conseqüência, foi a dificuldade da fiscalização desses programas de CIHs pelos agentes das secretarias de vigilância sanitária. Sendo amplamente reconhecido o problema crônico desse setor, com denúncias de corrupção e recursos humanos também qualitativa e quantitativamente deficientes - ainda mais, nesse caso, sem oferecer treinamento específico -, como poderiam esses técnicos, munidos apenas da determinação legal reconhecerem, avaliarem, orientarem e exercerem punições para os problemas encontrados em cada hospital e se eles estavam de fato relacionados à ocorrência dessas infecções? Teriam então, que se considerarem satisfeitos com a confirmação no "papel" da existência dessas CCIHs, com os relatórios sobre a sua incidência, assim como, a avaliação superficial dos recursos tecnológicos disponíveis, sem a possibilidade de averiguar a adequação de sua utilização e de avaliar a qualificação dos recursos humanos existentes para esses procedimentos.

Mesmo após o episódio da morte do presidente Tancredo Neves em 1985, 
vítima de IH, e as várias outras ações do MS para controlar ainda mais a questão, seja através de manuais, cursos de treinamentos (tendo atingido cerca de 140000 profissionais que trabalhavam com essa questão nos hospitais) e várias outras legislações para a utilização de produtos e equipamentos hospitalares, a situação não se modificou significativamente. Em 1993, dez anos após a primeira legislação, o próprio MS reconhecia a pouca efetividade de suas ações, concluindo que apenas $10 \%$ dos hospitais mantinham CCIHs (COCIN, 1993).

De outra forma, as condições fornecidas pelo MS (COCIN, 1993) para reverter a constatação acima - descentralização das ações, realização de estudos nacionais para conhecer a prevalência dessas IHs, ensino formal específico para estudantes da área da saúde e o cumprimento da nova Portaria 930/92 (BRASIL:1992) - facilmente se esvaziam, ao não se enxergar outras realidades determinantes, numa dimensão mais global.

Como exemplo, tome-se as condições de trabalho nessas área, dadas por recursos humanos qualitativa e quantitativamente deficientes, marcados pelo baixo salário e alta rotatividade. Outra situação é dada pelo agravamento da crise econômica e, consequentemente, o aumento do desemprego, da concentração de renda assim como, das diversas dificuldades para o implantar o SUS, contribuindo diretamente para deteriorar um sistema de saúde que já estava em crise e conduzindo a um estado de calamidade da assistência médica: superlotação, desativ ação de leitos, recusa de pacientes, fechamento de hospitais.

Diante desse quadro mais global, há que se perguntar se a mera existência de CCIHs nos hospitais e a exuberante legislação governamental específica ao problema se constitui em condição suficiente para resolver a questão e oferecer uma melhor qualidade de assistência hospitalar. Questão que se pretende responder, no próximo item.

\section{A IMPLEMENTAÇÃO DAS AÇÕES DE CONTROLE DE INFECÇÕES HOSPITALARES}

O controle das IHs no Brasil, institucionalizado sob ação governamental através da organização de CCIHs utiliza como instrumento básico a vigilância epidemiologica (VE), constituida pelas seguintes fases: a) eventos a serem investigados; b) coleta sistemática de dados; c) consolidação e tabulação dos dados; d) análise e interpretação dos dados e a sua divulgação. Em outras palavras, baseando-se no saber da epidemiologia tradicional e, portanto, sob concepção multicausal para a ocorrência desses eventos.

$\mathrm{Na}$ análise do processo de trabalho dessas CCIHs, entretanto, foi possível apreender que apesar delas estarem sob uma concepção multicausal, ou 
seja, reconhecerem as diversas causas e riscos para a ocorrência de IHs, inclusive, as diferentes condições de saúde da clientela a ser atendida, a vigilância epidemiologica se restringe somente aos procedimentos hospitalares. Com isso, esse processo acaba negando a sua propria concepção (multicausal) e realizam um trabalho unicausal-bacteriológico, ou seja, a VE fica limitada ao movimento de investigar as diferentes formas de transmissão dos microorganismos e as diferentes formas de destrui-los ou de impedir a sua invasão no âmbito hospitalar.

Com isso e, paradoxalmente, os resultados dessa investigação, delimitados às práticas clínicas, se de um lado, apontam as suas causas para esse modelo, evidenciando suas iatrogenias e colocando aparentemente em xeque as suas práticas de intervenção no corpo biologico, de outro, fortalecemno ainda mais, favorecendo o desenvolvimento de mais pesquisas sob esse paradigma e a evolução vertiginosa de suas técnicas instrumentalizadoras.

É pois, sob a concepção bacteriológica que o controle dessas infecções é realizado, estabelecendo a continuidade de incorporação de recursos como antibióticos, esterilizantes, desinfetantes, anti-sépticos e barreiras microbiológicas das quais, a revolução dos descartáveis faz parte. Ou seja, propicia-se a manutenção do círculo "vicioso" de desenvolvimento dos recursos técnicos para "combater" essas infecções, sendo eles mesmos, em grande parte, fatores condicionantes para a sua ocorrência.

Outrossim, a necessidade dada por esse processo de trabalho nega também o reconhecimento generalizado de que o controle dessas infecções propicia a contenção dos custos hospitalares. Se, os casos de IHs, quando porventura diminuem e, com isso, diminuem também os gastos diretos com o seu tratamento adicional, o custo indireto para manter esse controle aprimoramento e incorporação de mais tecnologia - e que nem sempre está sendo contabilizado, aumenta cada vez mais. Isso contribui, evidentemente, para que o gasto social com essa forma de assistência continue se mantendo desproporcionalmente alto, em relação a outras demandas de saúde e em relação aos benefícios dela decorrentes. Por conclusão, a concepção dada ao objeto, para justificar essa forma de controle é diferente do objeto real.

De outra forma, o conhecimento coletivo desse objeto, nessas condições, apresenta-se sob a forma de generalizações técnico-científicas, favorecendo o reconhecimento do processo de ocorrência dessas infecções e o seu controle de forma neutra e igual para todas as pessoas e hospitais, portanto, elaborando uma compreensão de igualdade social nessa assistência. Assim realizadas, essas práticas de controle reduzem o objeto a um recorte meramente biológico, negando a sua historicidade e, portanto, as outras dimensões para a sua ocorrência, como a sua relação com o desenvolvimento do modelo clínico e, no seu particular, com o modo próprio do estabelecimento dessa assistência no país. 


\section{CONCLUSÃO E CONSIDERAÇÕES FINAIS}

O presente estudo permitiu apreender inicialmente, que a ocorrência de IHs está estreitamente relacionada com a evolução da assistência hospitalar e que suas formas predominantes de manifestação estão intrinsecamente relacionadas às concepções dominantes do processo saúde-doença e de suas práticas de intervenção. Foi possível perceber também, que a necessidade para o seu controle somente ampliou-se além do locus do hospital e assumiu uma conotação política, quando o modelo predominante de assistência - o clínico - atingia um alto grau de desenvolvimento e de tecnologização, influenciando inclusive, a medicalização da sociedade, em meados deste século.

Em que pese tratar-se de um fenômeno mundial, foi possível apreciar a sua manifestação particular no país, determinada pelos rumos das políticas de saúde adotadas, que valorizaram crescentemente a assistência hospitalar privada, desigual e absorvedora voraz de recursos públicos.

Não foi por acaso também, que as demandas para o seu controle se intensificaram no país, a partir da década de 80. Sabidamente, esse foi o período de transição democrática, de amplo reconhecimento da crise na área de saúde, com as políticas adotadas até então. Portanto, essas demandas repercutiram junto com várias outras demandas por mudanças no sistema de saúde, seja no âmbito de uma reforma geral, seja em setores específicos.

No reconhecimento do processo de trabalho dessas CCIHs, mostrou-se a sua subordinação ao modelo que pretende controlar, portanto, não permitindo modificar significantemente a forma de intervenção no objeto, sob esse paradigma. Ao contrário, até o reproduz e reforça. Com isso, esse projeto de $\mathrm{CIH}$, até certo ponto, acaba se contrapondo ao projeto de reforma geral do sistema de saúde institucionalizado pelo SUS, cuja premissas, em plenas condições de implementação se revelariam em importante contribuição ao controle dessas infecções, ao "atacar" outros níveis determinantes do problema.

De outra forma, esse projeto se contrapõe ao do SUS até certo ponto, porque apesar do inegável salto qualitativo da concepção do SUS acerca do processo saúde-doença, ele ainda não cons egue superar esse mesmo problema paradigmático: a predominância do modelo médico-biológico.

Assim, ainda que se constate atualmente no país a ampliação dos direitos de cidadania e, no caso do setor saúde, vigore uma concepção contrahegemônica do processo saúde-doença e uma nova organização de serviços através do SUS, essa estrutura político-jurídica, por si s6, não basta para concretizar mudanças essenciais, mesmo sob condições objetivas já dadas. A tarefa, portanto, não é somente política. Ela dependerá também da construção de novos saberes que instrumentalizem e possibilitem a transformação da prática. Saberes e instrumentos, por sua vez, que permitam justamente 
expressar os diferentes interesses e necessidades, assim como, considerar a importância de sua interrelação.

Nesse contexto, é preciso redimensionar aqui, sob novos paradigmas, duas categorias presentes o tempo todo neste estudo e também já amplamente reconhecidas como condições imprescindíveis ao processso de reforma democrática não somente no setor saúde, mas de toda a organização social: qualidade e recursos humanos.

LACERDA, R.A. et al. Hospital infections in Brazil. Governmental actions for its control while expression of social politics in health area. Rev.Esc.Enf.USP, v.30, n.1, p.93-115, Apr. 1996.

The authors study the hospital infections evolution em Brasil and the demands for its control until its establishment by governmental actions. For a better understanding and analysis of the social actors'dispute process, their needs and interests and the relation with the governmental sector to the establishment of a certain state politics, a theoretical reference that enabled to eleborate the whole of social structure elements was searched. This theoretical reference should also take the filled of the relation between Society, State, Actors and Social Politics as its main question. In order to allude to these specific actions and its intervention range, it was necessary to make a distinction between the state politics modalities and the implementation responsabilities. Based on empirical material, it was possible to trace these demands, conforming on technological-assistencial models thorough the working porcess indicators. Other empirical categories levels was demanded to approach to the theoretical reference: specific conjectures, welfare medical assistance, the clinical intervention model and the quality movement. All the time, the analysis of the demands and the stablished project aimed the relation between the instruments and their purposes with themselves and with the health general politics, showing its implications.

UNITERMS: Hospital infection. Health politics.

\section{REFERÊNCIAS BIBLIOGRÁFICAS}

ASSOCIAÇÃO pode reunir parentes das vítimas de infecção hospitalar. O Estado de São Paulo, 04 mai. 1983.

BRAGA, J.C. de S; PAULA, S.G. de. Saúde e previdência. Estudos de política social. Rio de Janeiro, Paz e Terra, 1985

BRASIL. Leis, etc. Decreto n. 77.052 de 19 de janeiro de 1976. Dispoe sobre a fiscalização sanitária das condiçōes de exercício de profissões e ocupações técnicas e auxiliares, relacionadas diretamente com a saúde. In: BRASIL. Ministério da Saúde. Manual de controle de infecção hospitalar. Brasília, Centro de Documentação do Ministério da Saúde, 1985. p.106-7. 
BRASIL. Leis, etc. Portaria RRJM n. 8 de 1 de junho de 1976 e Ordem de Serviço SAM n. 39.24 de 24 de agosto de 1976. Instituto Nacional de Previdência Social. In: ZANON, U.; NEVES, J. Infecões hospitalares: prevenção, diagnóstico e tratamento. Rio de Janeiro, MEDSI, 1987.

BRASIL. Leis, etc. Lei n. 6437 de 20 de agosto de 1977. Configura infrações à legislação sanitária federal, estabelece as sançōes respectivas, e dá outras providências. In: BRASIL. Ministério da Saúde. Manual de controle de infecção hospitalar. Brasília, Centro de Documentação do Ministério da Saúde, 1985. p.107-12.

BRASIL. Leis, etc. Ordem de Serviço SAM n. 44.1 de 30 de outubro de 1978. Instituto Nacional de Previdência Social. In: ZANO, U.; NEVES, J. Infecçðes hospitalares: prevenção, diagnóstico e tratamento. Rio de Janeiro, MEDSI, 1987.

BRASIL. Leis, etc. Portaria n. 196 de 24 de junho de 1983. Ministério da Saúde. Dispõe sobre instruçðes para o controle e prevenção das infeç̧ðes hospitalares. In: BRASIL. Ministério da Saúde. Manual de controle de infecção hospitalar. Brasília, Centro de Documentaça do Ministério da Saúde, 1985. p.101.

BRASIL. Leis, etc. Portaria 930 de 27 de agosto de 1992. Dispõe sobre normas e instruções para o controle das infeç̧ōes hospitalares no país (revoga a Port 196/83). Diário Oficial da União., Brasília, 4 de set. de 1992. Seção I, p. 12279-82.

CHRISTÓVÃO, D. de A. Esterilização do material hospitalar. Rev. Paul. Hosp., v.4, n.8, p.15-31.

COCIN. Editorial. Brasília, Bol Inf. Coord. Cont. IH do MS, v. 1, n.1, 1993.

COSTA, N. do R. Política pública, direitos e interesses: reforma sanitária e a organização sindical brasileira. Rio de Janeiro, ENSP/FIOCRUZ/UFF, s.d. /mimeografado/

DEMO, P. apud MINAYO, M.C. de S. O desafio do conhecimento. Pesquisa qualitativa em saúde. São Paulo, Hucitec, 1992.

DRAIBE, S. Rumos e metamorfoses. Estado e industrialização no Brasil 1930/1960. Rio de Janeiro, Paz e Terra, 1985.

FIORI, J.L.; KORNIS, G.E.M. Além da queda: economia e política numa década enviesada. In: GUIMARĀES, R.; TAVARES, R. Saúde e sociedade no Brasil Anos 80. Rio de Janeiro, Abrasco-Dumará, 1994. Cap. I, p.1-42.

FRANCISCONI, C.W. Ato cirúrgico e infeç̧סes pós-operatórias. Rev. Paul. Hosp., v.7, n.2, p. $12-6,1959$.

LACERDA, R. A. Infeç̧ס̄es hospitalares no Brasil. Ações governamentais para o seu controle enquanto expressão de políticas sociais na área de saúde. São Paulo, 1995. Tese

(Doutorado) - Escola de Enfermagem, Universidade de São Paulo.

FURTADO, C.M. O Brasil pós-"milagre". 4.ed., Rio de Janeiro, Paz e Terra, 1981.

LUZ, M.T. As instituições médicas no Brasil. Instituição e estratégia de hegemonia. Rio de Janeiro, Graal, 1979. 
MACHADO, E.M. ET AL. Estudos sobre estafilococcias III: levantamento de portadores no berçário do hospital das clínicas, antibiograma e fagotipagem das amostras obtidas. Rev. Hosp. Clin. Fac. Med. USP., v. 16, n.2, p.123-34, 1961.

MARTINS, L. Estado capitalista e burocracia no Brasil pós 64. São Paulo, Paz e Terra, 1985.

MERHY, E.E. São Paulo de 1920 a 1948. A saúde pública como política. Os movimentos sanitários, os modelos tecno-assistenciais e a formação de políticas governamentais. São Paulo, 1991. Tese (doutorado) - Departamento de Medicina Preventiva da Universidade Estadual de Campinas.

MINAYO, M.C. de S. O desafio do conhecimento: pesquisa qualitativa em saúde. São Paulo, Hucitec, 1992.

OFFE, C.; LENHARDT, G. Teoria do Estado e política social. In: OFFE, C. Problemas estruturais do Estado capitalista. Rio de Janeiro, Tempo Brasileiro, 1984. Cap. I: Força de trabalho e poder da sociedade.

OLIVEIRA, J.A. de A.; TEIXEIRA, S.M.F. (Imprevidência social. 60 anos de história da previdência social no Brasil. 2.ed. Rio de Janeiro, VOZES-ABRASCO, 1989.

ROSSI, S.S. Desenvolvimento de políticas de saúde nos anos 80 . O caso brasileiro. Acordo técnico NEPP/UNICAMP/OPAS. São Paulo, Escola de Administração de Empresas da Fundação Getúlio Vargas/Curso de Administração Hospitalar e de Sistemas de Saúde (CEAHS), s.d. /mimeografado/

RUIZ, E.A.C. Propostas de integração das instituições de saúde. In: MARSIGLIA, R.; SPINELLI, S. Organização da Assistência Previdenciária e Administração de Servicos de Saúde. São Paulo, Centro Acadêmico Manoel de Abrei da Faculdade de Ciências Médicas da Santa Casa de São Paulo, s.d. p.57-68 (texto, 4). 
I - Concepções sobre a ocorrência de infecções hospitalares, ações demandadas e suas finalidades.

\begin{tabular}{|c|c|c|}
\hline CONCEPÇÕES* & AÇÕES & FINALIDADE \\
\hline $\begin{array}{l}\text { AMBIENTAL } \\
\text { As infecções são transmitidas diretamente, através de } \\
\text { microorganismos presentes no ar ambiente. }\end{array}$ & $\begin{array}{l}\text { Estabelece ações como saneamento do meio, } \\
\text { Produtos químicos germicidas para desinfecção } \\
\text { do ambiente, controle de portadores, barreiras } \\
\text { microbiológicas (ex.: paramentação), planta física } \\
\text { com fluxos unidirecionais de ar, material e } \\
\text { pessoal, etc, isolamento. }\end{array}$ & $\begin{array}{l}\text { Redução de microorganismos no ar } \\
\text { ambiente, seja destruindo-os, seja } \\
\text { impedindo a sua liberação elou circulação. }\end{array}$ \\
\hline $\begin{array}{l}\text { - PROCEDIMENTAL } \\
\text { Infecções são transmitidas por veiculação, através dos } \\
\text { procedimentos técnicos (funcionário-paciente, material**- } \\
\text { paciente) e contato paciente-paciente. } \\
\text { - FLORA HUMANA } \\
\text { Infecções causadas pela flora humana normal, seja por } \\
\text { alteração de suas resistências, seja por migração, através } \\
\text { de procedimentos invasivos. }\end{array}$ & $\begin{array}{l}\text { Desenvolve técnicas assépticas para a } \\
\text { realização dos procedimentos e para o atamento } \\
\text { dos artigos médicos-hospitalares que entram em } \\
\text { contato com o paciente. } \\
\text { Desenvolve técnicas e produtos de anti-sepsia, } \\
\text { estudos bacteriológicos para o reconhecimento } \\
\text { do comportamento e da resistência dessa flora } \\
\text { para a dos antibióticos, aperfeiçoamento dos } \\
\text { procedimentos invasivos. }\end{array}$ & $\begin{array}{l}\text { Tem a finalidade de impedir a veiculação dos } \\
\text { microorganismos, seja destruindo-os seja } \\
\text { estabelecendo barreiras microbiolóicas. }\end{array}$ \\
\hline $\begin{array}{l}\text { MÚLTIPLA } \\
\text { Conjuga todas ou duas concepções acima, com } \\
\text { momentos de predominância de umas delas. }\end{array}$ & $\begin{array}{l}\text { Utiliza vigilância epidemiológica com a análise } \\
\text { prospectiva de fatores de risco. }\end{array}$ & $\begin{array}{l}\text { Tem a finalidade de e controlar as causas } \\
\text { possíveis de transmissão de microorganismos } \\
\text { no hospital. }\end{array}$ \\
\hline $\begin{array}{l}\text { - MULTICAUSAL } \\
\text { Considera que, além de todas essas possibilidades, a } \\
\text { infecção também está relacionada com os aspectos } \\
\text { individuais do paciente (idade, estado, nutricional, } \\
\text { condiçções sócio-econômicas, doença de base, etc. }\end{array}$ & $\begin{array}{l}\text { Utiliza vigilância epidemiológica com a análise } \\
\text { prospectiva de fatores de risco. }\end{array}$ & $\begin{array}{l}\text { Tem a finalidade de reconhecer e controlar } \\
\text { todas as causas possíveis de transmissão e as } \\
\text { condições de susceptibilidade do paciente. }\end{array}$ \\
\hline
\end{tabular}

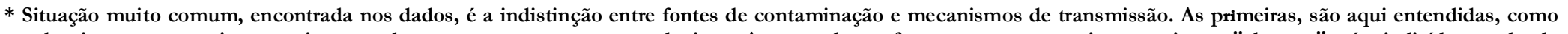

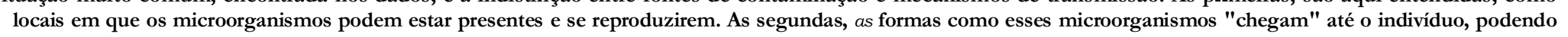
causar infecção.

** Entenda-se por material, não somente o instrumental técnico, mas todo o arsenal terapêutico como água, alimentos, medicamentos, etc. 
II - Demonstrativo dos tipos de infecções hospitalares na evolução da assistência hospitalar.

\begin{tabular}{|c|c|c|c|}
\hline PERÍODO & AÇÃO ASSISTENCIAL & $\begin{array}{l}\text { TIPO DE INFECÇÃO HOSPITALAR } \\
\text { PREDOMINANTE }\end{array}$ & MODO DE TRANSMISSÃOO \\
\hline $\begin{array}{l}\text { Idade média - } \\
\text { início do } \\
\text { capitalismo (Séc. } \\
\text { XVII) }\end{array}$ & $\begin{array}{l}\text { Expectante } \\
\text { - Recolhimento e alojamento de } \\
\text { indigentes e enfermos. }\end{array}$ & $\begin{array}{l}\text { EXÓGENAS ESPECÍFICAS } \\
\text { Causadas por microorganismos não } \\
\text { pertencentes à flora humana normal, com } \\
\text { características de apresentarem um quadro } \\
\text { analítico-clínico específico, tipo das doenças } \\
\text { comunitárias. EX: B. Koch - tuberculose } \\
\text { Vibrião colérico - cólera. }\end{array}$ & $\begin{array}{l}\text { Vias aéreas superiores e por veículos } \\
\text { (água, solo, mãos, etc). }\end{array}$ \\
\hline $\begin{array}{l}\text { Século XVII até } \\
\text { inicio do Séc. XX }\end{array}$ & $\begin{array}{l}\text { - Intervenção no corpo, na forma } \\
\text { predominante de procedimantos } \\
\text { invasivos, sem os recursos de } \\
\text { assepsia e de antimicrobianos. }\end{array}$ & $\begin{array}{l}\text { EXÓGENEAS E ENDÓGENAS } \\
\text { INESPECÍFICAS } \\
\text { Causadas por microoganismos pertencentes } \\
\text { ou não à flora humana normal, com a } \\
\text { característica de apresentarem infecções em } \\
\text { vários "sítios", a partir das condições de sua } \\
\text { invasão e reprodução no organismo. Ex: } \\
\text { infecções urinárias, respiratórias, de ferida } \\
\text { cirúrgica, etc. }\end{array}$ & $\begin{array}{l}\text { Predominantemente, por veiculação, } \\
\text { através de procedimentos invasivos } \\
\text { localizados (com as mãos e } \\
\text { instrumentais) e por migração de } \\
\text { flora humana (saindo de seu "habitat" } \\
\text { normal no organismo, para áreas } \\
\text { estéreis ou isentas dessa flora) }\end{array}$ \\
\hline Meados Séc. XX & $\begin{array}{l}\text { - Intervenções no corpo, com } \\
\text { recursos de assepsia e de } \\
\text { medicamentos antimicrobioanos e } \\
\text { imunodepressivos. }\end{array}$ & $\begin{array}{l}\text { ENDÓGENAS INESPECÍFICAS } \\
\text { MULTIRESISTENTES } \\
\text { Causadas por microorganismos da flora } \\
\text { humana, com a característica de se } \\
\text { apresentarem com resistência alterada aos } \\
\text { antimicrobianos. }\end{array}$ & $\begin{array}{l}\text { Pelo ambiente (por liberação da flora } \\
\text { cutâneo-mucuosa), por veiculação e } \\
\text { migração. }\end{array}$ \\
\hline
\end{tabular}

